\title{
Observation of Built-up Edge Formation on a Carbide Cutting Tool with Machining Aluminium Alloy under Dry and Wet Conditions
}

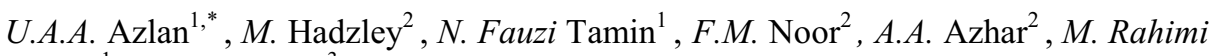 \\ Yusoff $^{1}$, N.Z. Noriman ${ }^{3}$ \\ ${ }^{1}$ Faculty of Engineering Technology, Universiti Teknikal Malaysia Melaka (UTeM), Hang Tuah Jaya, \\ 76100 Durian Tunggal, Melaka, Malaysia \\ ${ }^{2}$ Faculty of Manufacturing Engineering, Universiti Teknikal Malaysia Melaka (UTeM), Hang Tuah \\ Jaya, 76100 Durian Tunggal, Melaka, Malaysia \\ ${ }^{3}$ Faculty of Engineering Technology, Universiti Malaysia Perlis (UniMAP), Aras 1, Blok S2, Kampus \\ UniCITI Alam Sungai Chuchuh, Padang Besar, 02100 Perlis, Malaysia
}

\begin{abstract}
This paper presents the morphology of built-up edge (BUE) formation under wet and dry conditions with low and high cutting speeds. The workpiece materials and cutting tools selected for this work were aluminium alloy and canela carbide inserts graded PM25. The cutting tools underwent turning operation machining tests and their performance was evaluated by the flank wear and observation of the tool wear area. The machining tests were conducted at different spindle speeds and feed rates while the cut depth was kept constant. The analysis showed that formation of the BUE was dominant at low cutting speeds in dry conditions, but in wet conditions at high cutting speeds, a better performance was exhibited in terms of wear analysis.
\end{abstract}

\section{Introduction}

Aluminium alloy is a lightweight material that has been widely used in manufacturing industries, especially in the automotive and aeronautics sectors. This is because of its superior mechanical behaviour; exhibiting good corrosion resistance, low density, high strength and low-cost material [1]. Despite the advantages of this aluminium, there are some difficulties machining this material especially when the cutting parameter is not applied correctly. In any machining process, apart from obtaining accurate dimensions, achieving a good surface quality and maximizing metal removal are also important criteria. Machining aluminium is normally applied in dry conditions whereby the processes are normally applied to finishing and cleaning environments. Therefore, machining aluminium sometimes produces quick tool wear due to high friction at the cutting interface [2].

There are other techniques such as wet cutting that are also applicable to cutting aluminium. The wet cutting technique reportedly produces longer tool life due to lower friction and a cooler environment [3]. However, using coolant will be hazardous to the

*Corresponding author: umar@utem.edu.my 
environment, and the availability of the material raises the question of which technique is better to machine this material. There are cases where machining aluminium may produce the best surface finish and the lowest tool wear in dry conditions when the cutting parameters are applied correctly. There are also cases where machining aluminium gave the worst surface finish and the highest tool wear in wet conditions when improper cutting parameters were applied [4]. Therefore, it is necessary to make a comparison between wet and dry conditions in order to evaluate the best surface finish and tool wear when machining Aluminium 2024. This paper investigates the tool wear of carbide cutting tools when machining aluminium alloy on wet and dry conditions at different cutting speeds. In this research, the evaluation of the machining performance of the cutting tools mentioned above depends on tool wear and tool life and wears mechanisms.

\section{Experimental procedures}

The aim of this work is to discover the performance value of the tool life of carbide cutting tools at several different cutting speeds on dry and wet conditions. The experiments were carried out on a MOMAC SM200X manual lathe machine. Since the manual lathe machine was used, 12 bars of workpiece materials were prepared at consistent cutting lengths of 127 $\mathrm{mm}$ long and $19 \mathrm{~mm}$ diameter for each cutting trial. The types of carbide tools used in this work were made from Canela insert grade PM25, and held by a PSBNR16-4R174.3-252512 tool holder. Mineral oil was used as the coolant for wet conditions. An optical microscope and a scanning electron microscopy (SEM) were used to determine tool wear and make observations of the edge tool profile. For this experiment, cutting speeds and feed rates were varied according to the machine settings, while the cut depth was kept constant at $1 \mathrm{~mm}$. Table 1 shows the cutting parameters used in this study.

Table 1. Cutting Conditions for Machining Tests (Depth of Cut: Constant $1 \mathrm{~mm}$, Cutting Conditions: Dry and Wet

\begin{tabular}{|c|c|c|}
\hline No. & Cutting speed (m/min) & Feed rate (mm/rev) \\
\hline 1 & 10,000 & 45.72 \\
\hline 2 & 15,000 & 66.04 \\
\hline 3 & 22,000 & 96.52 \\
\hline 4 & 32,000 & 142.24 \\
\hline 5 & 47,000 & 210.82 \\
\hline 6 & 71,000 & 307.34 \\
\hline
\end{tabular}

\section{Results and discussion}

Fig. 1 shows a comparison plot of wet and dry cutting conditions in terms of tool wear value. For dry cutting, the flank wear was considered high at the cutting speed of 10,000 $\mathrm{m} / \mathrm{min}$ and it decreased steadily between $22,000 \mathrm{~m} / \mathrm{min}$ to $71,000 \mathrm{~m} / \mathrm{min}$. For wet cutting, the graph shows that low flank wear was recorded at a starting point of $10,000 \mathrm{~m} / \mathrm{min}$, increased tremendously at $15,000 \mathrm{~m} / \mathrm{min}$, gradually decreased at $22,000 \mathrm{~m} / \mathrm{min}$ and slightly increased at the end of $71,000 \mathrm{~m} / \mathrm{min}$. It clearly shows that the flank wear in wet cutting was lower than in dry cutting for most of the cutting conditions, except at the higher cutting speed of $71,000 \mathrm{~m} / \mathrm{min}$. 


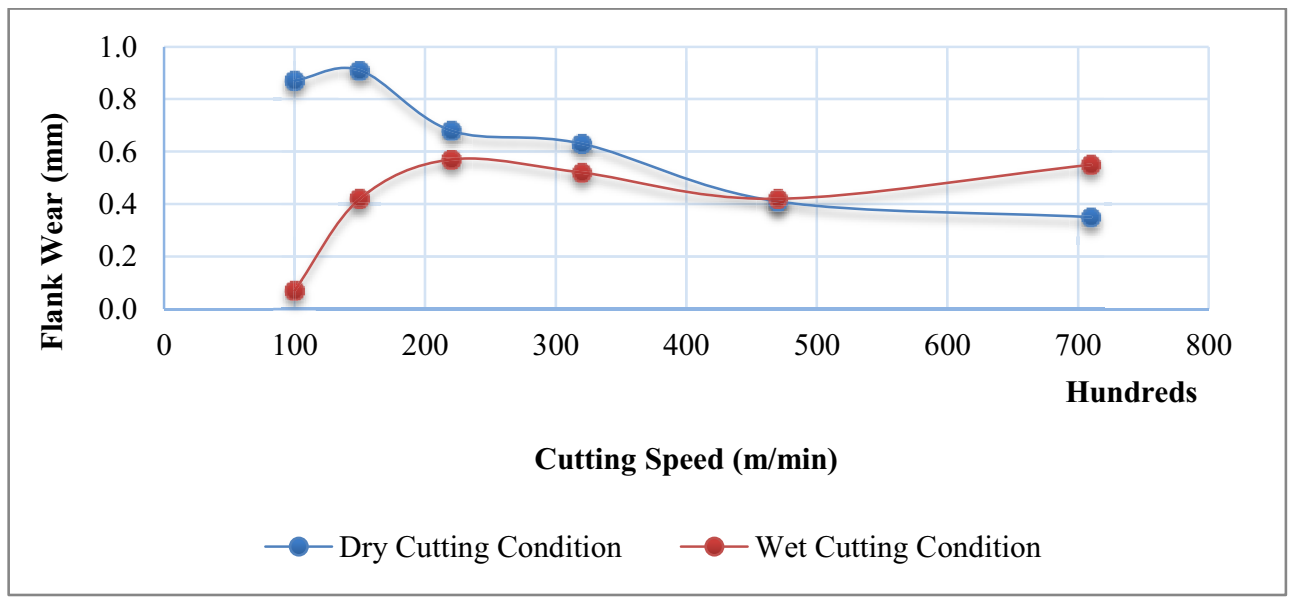

Fig. 1. Comparison between Wet and Dry Cutting Conditions

Fig. 2 and Fig. 3 show the images of flank wear of the cutting tool taken by SEM in dry and wet conditions respectively. The images clearly illustrate the formation of BUE at some locations at the edge of the tool wear area. This was observed especially during machining in dry conditions. BUE can be described as the machined material building up on the cutting edge due to the material having a tendency to anneal itself to the cutting edge of a tool. It occurs most frequently on softer metals with lower melting points, and it can be prevented by increasing cutting speeds and using lubricant. During machining, high temperatures generated at the tool-chip interface resulted in some of the material melting. As a result, this material gradually attached to the cutting tool as a permanent structure in the form of bulk layer [5].

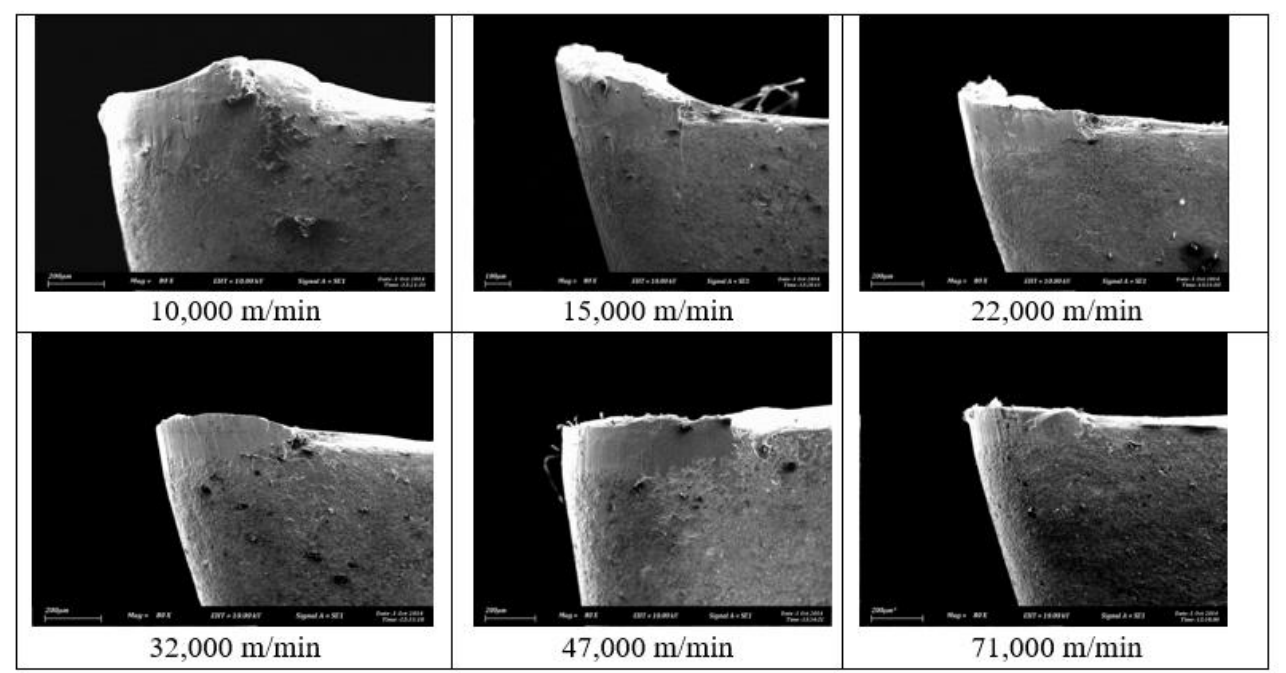

Fig. 2. Image of flank wear of the cutting tool in dry cutting conditions 


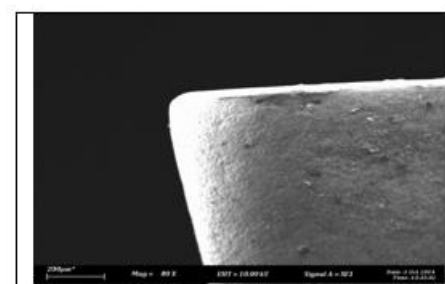

$10,000 \mathrm{~m} / \mathrm{min}$

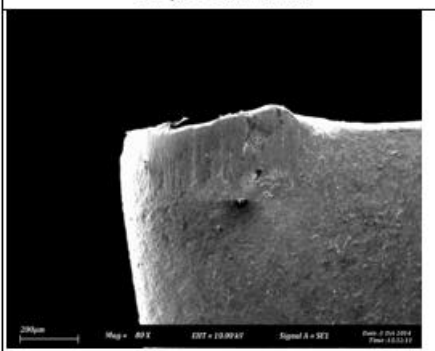

$32,000 \mathrm{~m} / \mathrm{min}$

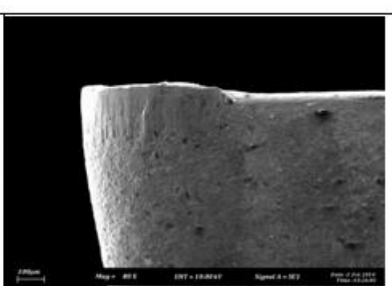

$15,000 \mathrm{~m} / \mathrm{min}$

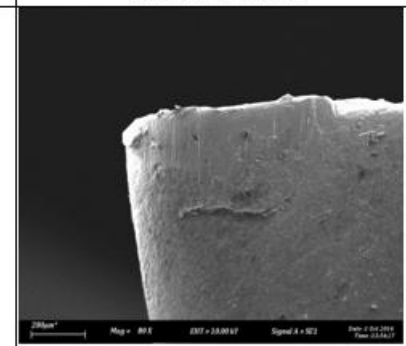

$47,000 \mathrm{~m} / \mathrm{min}$

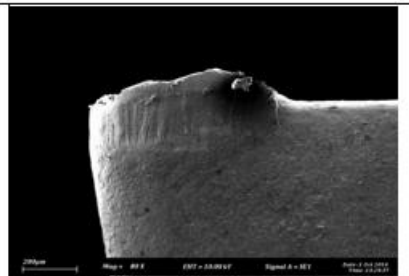

$22,000 \mathrm{~m} / \mathrm{min}$

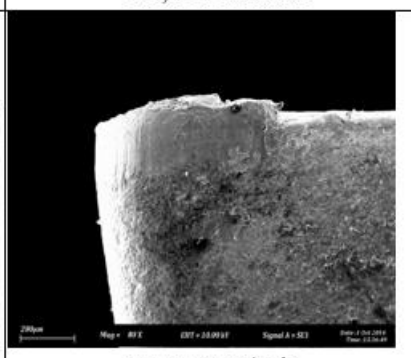

$71,000 \mathrm{~m} / \mathrm{min}$

Fig. 3. Image of flank wear of the cutting tool in wet cutting conditions

The existence of BUE is highly dependent on spindle speed and feed rate. The additional appearance of BUE altered the tool nose radius, resulting in changes in the toolchip contact as well as cutting force. Changes in the tool-chip contact may result in surface finish of the machined component while change in the cutting force may increase the risk of tool breakage [6]. It should be noted that, in dry cutting conditions, the formation of BUE was only observed at low cutting speeds. For instance, BUE significantly appeared at cutting speeds of $10,000 \mathrm{~m} / \mathrm{min}, 15,000 \mathrm{~m} / \mathrm{min}$ and $22,000 \mathrm{~m} / \mathrm{min}$ only. Conversely, the BUE formation was not clearly observed at the high cutting speeds of $32,000 \mathrm{~m} / \mathrm{min}$, $47,000 \mathrm{~m} / \mathrm{min}$ and $71,000 \mathrm{~m} / \mathrm{min}$. This phenomenon occurred due to the sliding action of the chip during high cutting speed. As the cutting speed increased, the sliding velocity of the chip that formed during machining increased tremendously. As a result, the force from the sliding chip slid the BUE immediately, leading to a gradual decrease in the BUE structure [7].

The appearance of BUE was observed to be minimized when wet cutting was performed, as shown in Fig. 3. The use of cutting fluids enabled heat to be dissipated away from the cutting zone, and at the same time, the fluid reacted as a lubricant to reduce the friction between the cutting tool and workpiece material. Additionally, the force from the overhead cutting fluids removed the chip formation which helped dispose of the chips that became entangled in the machining zone, decreasing the contact length between chip and control chip formation. This consequently had a positive effect on improved machining performance.

\section{Conclusions}

This paper presents the results in terms of tool performance when turning Aluminium Alloy 2014 in wet and dry conditions. The process appears to offer an economic advantage over completely dry machining current aluminium alloys. Based on the experimental findings the following conclusions were made:

- Flank wear is higher at lower cutting speeds and lower feed rates and slightly decreased when the speed is increased in dry cutting conditions. Conversely, flank 
wear in wet cutting conditions is lower until $47,000 \mathrm{rev} / \mathrm{min}$ and constantly uniform from then onwards.

- The tool wear on wet cutting is lower than on dry cutting due to the presence of cutting fluid that reduced the friction and dissipated heat away from the contact zone.

- BUE is significant in both cutting conditions, but it is most effective in dry cutting.

- The presence of cutting fluid can reduce the formation of BUE at the cutting zone.

Special thanks to Ministry of Higher Education Malaysia (MOHE) (FRGS/1/2014/TK04/FTK/02/F00207) and Universiti Teknikal Malaysia Melaka for their financial support.

\section{References}

1. S. Kalpakjian, S.R. Schmid. 4th ed. New Jersey: Prentice-Hall (2001)

2. A.B. Mohd Hadzley, A. Siti Sarah, R.A. Raja Izamshah, A.A. Mohd, M.S. Kasim, M.A. Sulaiman, M.R. Nurul Fatin, Appl. Mech. Mater., 465-466 (2014)

3. M.S. Kasim, C.H. Che Haron, J.A. Ghani, M.A. Azam, R. Izamshah, M.A. Md Ali, M.S.A. Aziz, J. Sci. Ind. Res. India., 73 (2014)

4. G. List, M. Nouari, D. Gehin, S. Gomez, J.P. Manaud, Y. Le Petitcorps, F. Girot, Wear., 259, 7(2015)

5. S. Atlati, B. Haddag, M. Nouari, A. Moufki, Tribol. Int., 90 (2015)

6. A. Gomez Parra, M.Alvarez Alco, J. Salguero, M. Batista, M. Marcos, Wear., 302, 1 (2015)

7. J. Kummel, J. Gibmeier, E. Muller, R. Schneider, V. Schulze, A. Wanner, Wear., 311, $1(2014)$ 